\title{
Comparison of elderly and young patient populations treated with deep brain stimulation for Parkinson's disease: long-term outcomes with up to 7 years of follow-up
}

\author{
Joshua A. Hanna, MD,, ${ }^{1,2}$ Tyler Scullen, MD,, ${ }^{1,2}$ Lora Kahn, MD, ${ }^{1,2}$ Mansour Mathkour, MD, ${ }^{1,2}$ \\ Edna E. Gouveia, MD, ${ }^{1}$ Juanita Garces, MD, ${ }^{1,2}$ Leah M. Evans, MS, ${ }^{1}$ Georgia Lea, MD, ${ }^{3}$ \\ David J. Houghton, MD, MPH, ${ }^{3}$ Erin Biro, MD, ${ }^{1,2}$ Cuong J. Bui, MD, ${ }^{1,2}$ \\ Olawale A. Sulaiman, MD, PhD, ${ }^{1,2}$ and Roger D. Smith, MD ${ }^{1,2}$
}

Departments of ${ }^{1}$ Neurosurgery and ${ }^{3}$ Movement Disorders, Ochsner Clinic Foundation, New Orleans; and ${ }^{2}$ Department of Neurosurgery, Tulane Medical Center, New Orleans, Louisiana

\begin{abstract}
OBJECTIVE Deep brain stimulation (DBS) is the procedure of choice for Parkinson's disease (PD). It has been used in PD patients younger than 70 years because of better perceived intra- and postoperative outcomes than in patients 70 years or older. However, previous studies with limited follow-up have demonstrated benefits associated with the treatment of elderly patients. This study aims to evaluate the long-term outcomes in elderly PD patients treated with DBS in comparison with a younger population.
\end{abstract}

METHODS PD patients treated with DBS at the authors' institution from 2008 to 2014 were divided into 2 groups: 1) elderly patients, defined as having an age at surgery $\geq 70$ years, and 2) young patients, defined as those $<70$ years at surgery. Functional and medical treatment outcomes were evaluated using the Unified Parkinson's Disease Rating Scale part III (UPDRS III), levodopa-equivalent daily dose (LEDD), number of daily doses, and number of anti-PD medications. Study outcomes were compared using univariate analyses, 1-sample paired t-tests, and 2-sample t-tests.

RESULTS A total of 151 patients were studied, of whom $24.5 \%$ were $\geq 70$ years. The most common preoperative Hoehn and Yahr stages for both groups were 2 and 3. On average, elderly patients had more comorbidities at the time of surgery than their younger counterparts ( $1 \mathrm{vs} 0, p=0.0001$ ) as well as a higher average LEDD (891 mg vs $665 \mathrm{mg}$, $p=0.008$ ). Both groups experienced significant decreases in LEDD following surgery (elderly $331.38 \mathrm{mg}, p=0.0001$; and young $108.6 \mathrm{mg}, p=0.0439$ ), with a more significant decrease seen in elderly patients (young $108.6 \mathrm{mg}$ vs elderly $331.38 \mathrm{mg}, p=0.0153$ ). Elderly patients also experienced more significant reductions in daily doses (young 0.65 vs elderly $3.567, p=0.0344$ ). Both groups experienced significant improvements in motor function determined by reductions in UPDRS III scores (elderly 16.29 vs young 12.85, $p<0.0001$ ); however, reductions in motor score between groups were not significant. Improvement in motor function was present for a mean follow-up of 3.383 years postsurgery for the young group and 3.51 years for the elderly group. The average follow-up was 40.6 months in the young group and 42.2 months in the elderly group.

CONCLUSIONS This study found long-term improvements in motor function and medication requirements in both elderly and young PD patients treated with DBS. These outcomes suggest that DBS can be successfully used in PD patients $\geq 70$ years. Further studies will expand on these findings.

https://thejns.org/doi/abs/10.3171/2018.4.JNS171909

KEYWORDS deep brain stimulation; Parkinson's disease; outcome measures; functional neurosurgery

$\mathrm{P}$ ARKINSON's disease (PD) is one of the most common age-related neurodegenerative diseases. ${ }^{18,21} \mathrm{PD}$ is treated both medically and surgically, with medical management attempting to supplement dopaminergic activity, as well as balancing dopaminergic and choliner- gic pathways. Although medical management can provide long-term functional mobility, it is associated with adverse side effects ${ }^{3}$ such as "wearing off" symptoms, and dyskinesia with levodopa therapy. ${ }^{20,35}$ The alternative to medical management is deep brain stimulation (DBS), which

ABBREVIATIONS DBS = deep brain stimulation; HY = Hoehn and Yahr; LEDD = levodopa-equivalent daily dose; MoCA = Montreal Cognitive Assessment; PD = Parkinson's disease; STN = subthalamic nucleus; UPDRS III = Unified Parkinson's Disease Rating Scale part III.

SUBMITTED August 7, 2017. ACCEPTED April 17, 2018.

INCLUDE WHEN CITING Published online September 28, 2018; DOI: 10.3171/2018.4.JNS171909. 
is widely accepted as the mainstay surgical treatment for patients who are not interested in medical therapy or their PD is refractory to it. . $, 5,18,21,23,27,29,36$

DBS surgery as an adjunct to medical therapy has proven to be highly effective at decreasing motor deficits, as evidenced by reductions in the Unified Parkinson's Disease Rating Scale part III (UPDRS III) scores reported in numerous studies at 6 months, 1 year, ${ }^{1,6,16,32,34,42}$ and 2 or more years postsurgery. $6,13,16,26,32,34,39,40,42$ Studies and trials examining the effects of DBS on medication dosages, quality of life,,$^{2,4}$ and cost analyses between medical and surgical therapies have been carried out at a number of centers. $15,17,31,33,41$

Special consideration for the use of DBS is given in the case of elderly patients, where an advanced age, generally defined as older than 70 years, at the time of surgery, may serve as a relative contraindication to DBS due to an increased incidence of comorbidities and surgery-related complications in this patient population. . $7,11,12,22,26,28,30,37,39$ It has been shown, independent of DBS-related treatment, that elderly patients have lower thresholds of tolerance for major procedures with common complications, including wound infection, pneumonia, hemorrhage, pulmonary embolism, neurological sequelae, and death. ${ }^{3,11,38}$ As a result, neurosurgeons have been reluctant to recommend elderly patients for DBS surgery, and thus the literature on surgical outcomes in this population has been variable. ${ }^{11}$ Still, PD remains a chronic progressive disease of the elderly, with a mean age at diagnosis of 60 years, and an average disease duration prior to DBS of 14 years. ${ }^{24}$ These population statistics, in addition to the projection that the number of PD patients is expected to double by 2030 as the result of an aging population, ${ }^{14}$ make the pertinence of age-related research an important consideration.

In a recent paper, ${ }^{25}$ we discussed DBS outcomes in our patient population of patients $\geq 70$ years. In the present article, we will directly compare this elderly population to a group of patients younger than 70 years in order to assess risks and benefits in the former. Some previous studies have shown comparable efficacy between young and elderly populations, with negligible risk of associated complications. , $7,11,12,28,30,37,39$ Elderly PD patients have also shown uniform benefits from DBS in medication and motor burdens when compared with their younger counterparts. $4,7,11,12,26,28,30,37,39$ As a result, several authors have suggested that advanced age should not be considered an absolute contraindication for DBS and that such patients may simply require a more meticulous preoperative workup. . $^{71,12,22,25,28,39}$ The purpose of this study was to evaluate the differences in outcomes between younger and elderly patient populations. We report our findings by evaluating long-term medical outcomes with up to 7-year follow-up in these 2 distinctive populations.

\section{Methods}

This retrospective study was approved by the institutional review board at the Ochsner Medical Center. Retrospective data were collected from patients treated by the senior author (R.D.S.), who performed the surgeries at Ochsner Medical Center between May 2008 and De- cember 2014. Patient consent was not obtained, as this was a retrospective chart review. PD patients who had undergone treatment with DBS were identified through retrospective analysis of patient data and collected into a password-protected, encrypted database. The patient data that were collected included sex, age at diagnosis, age at surgery, PD subtype, modified Hoehn and Yahr (HY) stage, motor scores, number of anti-PD medications before and after surgery, and the number of medication doses before and after the surgery. Patients were divided into 2 groups depending on their age in years at the time of surgery. Those with an age $\geq 70$ years were considered elderly, while those with an age $<70$ years were considered young. Effects of DBS on patients' anti-PD medication requirements were evaluated using levodopa-equivalent daily dose (LEDD), as previously described. ${ }^{24}$ Patients were evaluated at baseline, and then again during postsurgical follow-up, using the motor score of the UPDRS III. Baseline characteristics between patients were compared using paired t-tests, 2-sample t-tests, and the Wilcoxon test to determine means, standard errors, and $\mathrm{p}$ values for statistical significance. The value for statistical significance was set at $\mathrm{p}<0.05$.

\section{Surgical Procedure}

Implantation of DBS electrodes in all 151 patients was accomplished with frameless stereotaxy using the Activa system (Medtronic). Fiducial screws were placed the day before implantation, and a CT scan of the head was obtained to merge with MRI for intraoperative neuronavigation. The next morning, the DBS electrodes were inserted under local anesthesia into the appropriate target with microelectrode recording and neurophysiological testing performed in concurrence with a neurologist and neurophysiologist with a $\mathrm{PhD}$ degree. With the patient in a satisfactory position, the electrodes were capped into place and buried under the scalp. The patient returned the following week for placement of the pulse generator under general anesthesia. Programming was initiated 1 or 2 weeks later.

\section{Results}

\section{Patient Demographics and Diagnoses}

A total of 151 patients who underwent DBS implantation were included in our study. Of these, 114 patients (75.5\%) were classified as young, and $37(24.5 \%)$ were classified as elderly. The average duration of postoperative follow-up was 40.6 months for the young cohort and 42.2 months for the elderly cohort ( $\mathrm{p}=0.681$ ). In the young group, 34 patients (29.8\%) underwent follow-up for 2 years or less, $50(43.9 \%)$ for 3-5 years, and $30(26.3 \%)$ for more than 5 years. In the elderly group, 8 patients $(21.6 \%)$ underwent follow-up for 2 years or less, 20 (54.1\%) for 3-5 years, and $9(24.3 \%)$ for more than 5 years. Of the patients included in our study, $74.56 \%$ of the younger cohort and $64.86 \%$ of the elderly cohort were male $(\mathrm{p}=0.351)$. The mean age at the time of diagnosis was 50.71 years for the younger cohort and 63.05 years for the elderly $(\mathrm{p}$ $=0.0001)$. At the time of surgery, the mean age for the younger population was 58.92 years (range 50-62 years, median 59 years), while the mean age for the elderly co- 
TABLE 1. Selected demographic data and disease characteristics according to age group of PD patients treated with DBS

\begin{tabular}{|c|c|c|c|}
\hline Parameter & $\begin{array}{l}\text { Young } \\
(n=114)\end{array}$ & $\begin{array}{l}\text { Elderly } \\
(n=37)\end{array}$ & $\begin{array}{c}p \\
\text { Value }\end{array}$ \\
\hline Mean age at Dx, yrs & 50.71 & 63.05 & $0.0001^{*}$ \\
\hline Mean age at op, yrs & 58.92 & 72.45 & $0.0001^{*}$ \\
\hline Mean time btwn Dx \& op, yrs & 11.32 & 11.97 & 0.3287 \\
\hline Disease subclassification, $\mathrm{n}(\%)$ & & & 0.1098 \\
\hline Akinesia, rigid dominant & 43 (37.72) & $8(25.71)$ & \\
\hline Tremor dominant & $71(62.28)$ & $29(78.38)$ & \\
\hline HY stage, n† & & & 0.3860 \\
\hline 1 & 9 & 2 & \\
\hline 1.5 & 14 & 2 & \\
\hline 2 & 46 & 15 & \\
\hline 2.5 & 1 & 0 & \\
\hline 3 & 29 & 7 & \\
\hline 4 & 7 & 6 & \\
\hline 5 & 2 & 0 & \\
\hline Mean no. of comorbidities & & & $0.0001^{*}$ \\
\hline 0 & 58 & 5 & \\
\hline 1 & 28 & 16 & \\
\hline 2 & 19 & 12 & \\
\hline 3 & 5 & 0 & \\
\hline 4 & 3 & 1 & \\
\hline 5 & 0 & 3 & \\
\hline 6 & 1 & 0 & \\
\hline \multicolumn{4}{|l|}{ MoCA score, $\%$ of patients } \\
\hline Normal & $92.11 \%$ & $78.38 \%$ & 0.04593 \\
\hline Abnormal & $7.89 \%$ & $21.62 \%$ & \\
\hline
\end{tabular}

$\mathrm{Dx}=$ diagnosis.

${ }^{*}$ Statistically significant.

† HY scores were collected for 140 patients.

hort was 72.45 years (range 70-81 years, median 72.22 years), indicating normally distributed data points $(\mathrm{p}=$ $0.0001)$. The time from diagnosis until surgery was 11.32 years in the young cohort and 11.97 years in the elderly ( $p$ $=0.329$ ). Elderly patients were older at the time of diagnosis, but no significant difference was found in the time from diagnosis to surgery between age groups. There was no difference in the HY scores between young and elderly patients, with the most common stage reported as 2, and 3 as the second most common. The most common subset of PD for both groups was tremor dominant $(62.28 \%$ of the young cohort and $78.38 \%$ of the elderly cohort, $\mathrm{p}=$ 0.1098 ), with rigid dominant occurring less commonly. At the time of surgery, elderly patients had an average of 1 comorbidity with as many as 5 , and younger patients had an average of 0 comorbidities with as many as $6(\mathrm{p}=$ 0.0001). Montreal Cognitive Assessment (MoCA) scores were found to be normal in $92.11 \%$ of patients $<70$ years and in $78.38 \%$ of patients $\geq 70$ years $(\mathrm{p}=0.04593)$ (Table 1). The main surgical indication for DBS was early wearing off of anti-PD medication and medication-induced motor fluctuation. The most common target for DBS was
TABLE 2. Long-term surgical outcomes in patients with PD treated with DBS according to age group

\begin{tabular}{ccrc}
\hline Parameter & Preop & Postop $^{*}$ & p Value \\
\hline Elderly patients & & & \\
\hline Mean UPDRS III score & 31.79 & 15.50 & $<0.0001 \dagger$ \\
\hline Mean no. of med doses $\ddagger$ & 11.54 & 7.97 & $0.0112 \dagger$ \\
\hline Mean LEDD, mg & 891 & 559.62 & $0.0008 \dagger$ \\
\hline Young patients & & & \\
\hline Mean UPDRS III score & 35.46 & 22.61 & $<0.0001 \dagger$ \\
\hline Mean no. of med dosesł & 9.00 & 8.35 & 0.0635 \\
\hline Mean LEDD, mg & 665 & 556.40 & $0.0439 \dagger$ \\
\hline
\end{tabular}

Med = medication.

* The average follow-up time was 38 months, with a range of 4-84 months.

† Statistically significant.

$\ddagger$ Reflects the total amount of medication doses patients required per day.

the subthalamic nucleus (STN; 141 patients), followed by the globus pallidus pars interna (7 patients) and the ventral intermediate nucleus (3 patients).

\section{Surgical Outcomes}

Long-term outcomes in PD patients treated with DBS showed a positive impact on motor functions in both the elderly and young populations, as indicated by improvements in UPDRS III scores. The mean preoperative UPDRS III score was 35.46 in younger patients and 31.79 in elderly patients $(\mathrm{p}=0.2308)$. Postoperatively, scores decreased to 22.61 in the young population and 15.5 in the elderly, which was significant between the groups $(\mathrm{p}=$ 0.00169 ) (Table 2). Patients experienced a similar reduction in average LEDD following surgery. The preoperative LEDD was $665 \mathrm{mg}$ and $891 \mathrm{mg}$ for young and elderly patients, respectively $(\mathrm{p}=0.00799)$. Postoperative LEDD was $556.40 \mathrm{mg}$ for the young population and $559.62 \mathrm{mg}$ in the elderly $(\mathrm{p}=0.81)$. Decreased LEDD was reflected by a similar decrease in the average number of required antiPD medication doses preoperatively (9.0 in the young and 11.54 in the elderly, $\mathrm{p}=0.0986)$ to postoperatively $(8.345$ in the young and 7.97 in elderly, $p=0.6124$ ). Comparing the mean difference between groups (Table 3), the elderly group experienced a significantly larger overall reduction in LEDD (young $108.6 \mathrm{mg}$ and elderly $331.38 \mathrm{mg}, \mathrm{p}=$ 0.0153 ) and number of anti-PD doses per day (young 0.65 and elderly $3.567, \mathrm{p}=0.0344)$. Therefore, significant reduction in the number of daily doses was experienced in the

TABLE 3. Comparison of the mean differences (preoperative mean - postoperative mean) between the 2 groups

\begin{tabular}{lccl}
\hline \multicolumn{1}{c}{ Parameter } & Young $(n=114)$ & Elderly $(n=37)$ & $p$ Value \\
\hline No. of meds/day & 0.0088 & 0.2162 & 0.266 \\
\hline No. of doses/day & 0.65 & 3.567 & $0.0344^{*}$ \\
\hline UPDRS III score & 12.85 & 16.29 & 0.1109 \\
\hline LEDD & 108.6 & 331.38 & $0.0153^{*}$ \\
\hline
\end{tabular}

* Statistically significant. 
elderly population compared with the younger population, allowing this population to reach the same postoperative averages as seen in younger patients despite higher preoperative baseline values. No significant difference was seen in the overall reduction in UPDRS III score (young 12.8 and elderly $16.29, \mathrm{p}=0.1109$ ), or the number of medications (young 0.0088 and elderly $0.2162, p=0.266$ ). MoCA scores remained stable with baseline values and long-term follow-up intervals $(p=0.04593$, Table 1$)$.

\section{Complications}

Complications and adverse effects in the younger patient cohort included infections in $3(1.9 \%)$ patients, leading to system removal. Additionally, 4 (2.6\%) patients had a worsening of speech, and $2(1.32 \%)$ patients had worsening gait. Kinking or fracturing of DBS leads was experienced by $2(1.32 \%)$ patients, one at 12 months postsurgery and the other at 2 years postsurgery. In both cases, the system was replaced. Lead malpositioning was experienced by $1(0.7 \%)$ patient at 1 month postsurgery, and lead migration was experienced by $1(0.7 \%)$ patient at 3 years postsurgery, both of which were replaced. One patient experienced diplopia consequent to a sixth nerve palsy that was corrected surgically, and another experienced minor bleeding along the lead track, leading to a self-resolving speech deficit. Complications and adverse effects in elderly patients included infection in 1 (2.7\%) patient, who was infected 2 weeks after a pulse generator replacement (4 years after the initial DBS placement), which was removed and subsequently replaced. Cultures drawn at the time grew Staphylococcus epidermidis.

\section{Discussion}

The purpose of this study was to compare the longterm impact of DBS in the treatment of PD between elderly and younger patient populations. In a previous analysis of the elderly population, we demonstrated efficacy of DBS for patients $\geq 70$ years. ${ }^{25}$ With this present study, however, we aimed to validate the option of surgical intervention for medically refractory PD in the elderly by comparing our previously reported outcomes to those of a younger control population within our operative database. In elderly populations specifically, progression to surgical intervention has been historically discouraged due to the perception of higher intra- and postoperative complications paired with poor coverage of DBS outcomes in the literature. $.7,711,12,22,25,26,28,30,37,39$ In our study, both young and elderly patient populations underwent DBS with predominant targeting of the STN (90\% of cases), and an average follow-up time of 3.4 years in the young population and 3.5 years in the elderly. We believe that such a combination of patient demographics, and a closely documented long-term follow-up may provide valuable insight into the efficacy of surgical therapy in PD as it applies to patient age.

\section{Clinical Characteristics}

The main indication for surgery in both groups of patients was the development of wearing off symptoms and dyskinesias, which are well-documented sequelae of long- term levodopa treatment. ${ }^{19,20,35}$ A significant reduction in the number of daily doses was experienced in the elderly population in comparison with the younger population. Similar disease durations from diagnosis to surgery between populations and increased LEDD requirements seen in the elderly suggest that elderly patients have a higher baseline tolerance to dopaminergic therapy. Following surgical intervention, a more significant reduction in LEDD was demonstrated by the elderly, allowing this population to reach the same postoperative averages as seen in younger patients, despite higher baseline values.

Concerning UPDRS III motor scores, the young and elderly populations exhibited comparable preoperative scores (35.46 in the young vs 31.79 in the elderly, $\mathrm{p}=$ 0.2308 ), with equivalent improvements seen between populations, despite a higher average postoperative UPDRS III score in the elderly $(\mathrm{p}=0.00169)$. Similar corresponding values were also seen between populations in terms of HY status. Taken together with the differences seen between populations in terms of LEDD reductions, these scores suggest equivalent disease response to DBS surgery between populations, despite an increased age at the time of operation in the elderly population. The resulting improvement in motor function with the corresponding reduction in medication dependence allows for an avoidance of negative symptoms associated with long-term dopaminergic therapy ${ }^{19,20,35}$ and provides relief from the stress and subjective burden associated with complex medication regimens by patients and their caregivers, ${ }^{14} \mathrm{a}$ scenario particularly relevant in elderly populations. Overall, patients experienced a mean $40 \%$ reduction in UPDRS III scores, which was consistent with both past short-term ${ }^{13,26,39,40}$ and long-term ${ }^{6,16,32,42}$ investigations. These numbers were not found to be significantly different between elderly and younger patients. It is important to note that a relatively low number of comorbidities was present within our elderly population (1.59) when compared with those typically reported in elderly PD patients, , 4, 11,12,22,26,28,30,37,39 which may act as a partial contributor to our positive treatment outcomes. Our experience would suggest that DBS is safe and effective for elderly patients, and when age should be taken into consideration, elderly age should not automatically preclude treatment during patient selection.

The power and significance of our study lies in its longterm follow-up. Several past analyses of elderly and young patient populations have demonstrated reductions in UPDRS III scores ${ }^{3}$ and daily required medication doses ${ }^{34}$ and improvements in quality of life,,$^{32}$ but these studies are limited to brief follow-up periods. Long-term studies are understandably rare, given the novelty of the procedure and the inherent variability of patient availability. Studies involving patient follow-up at 8 or more years postsurgery have populations ranging from 14 to 20 individuals, ${ }^{6,16,42}$ with one successfully monitoring 19 patients for 20 years or more..$^{38}$ These studies are especially important as the initial gains seen with DBS for PD may diminish with time, ${ }^{42}$ especially in elderly populations, ${ }^{28}$ and further investigations with larger sample sizes are needed to better characterize and evaluate such events. In this study, we report positive findings from patients with averaged followups of over 3 years, with over a quarter (36 total patients) 
doing so at 5 or more years, with a high range of 7 years. Additionally, short-term, medium-term, and long-term follow-up data points are equally represented in our findings, providing a longitudinal perspective. This is especially important because of the decreased long-term efficacy of DBS that has historically been observed in elderly patients. ${ }^{31}$ It is important to note that such a phenomenon was not demonstrated in our study, and it is our hope to carry such analyses into the future so that we may further contribute to this vital growing body of research.

Previous studies that have reported on DBS targeted at the STN in the elderly population have yielded a range of results. One such study by Dafsari et al. ${ }^{10}$ showed varied favorable results for age groups $<59,60-69$, and $>70$ years. DBS was beneficial for the younger patients, most pronounced in terms of outcome measures for cognition, motor complications, LEDD, and quality of life. However, the study was limited to a 5-month follow-up period. Further follow-up would have been needed to assess the longterm effects in each age category, especially those $>70$ years. Similarly, a short- to midterm comparison study by $\mathrm{Chiou}^{8}$ reported improved outcomes in both groups, where the age group of $>70$ years showed less pronounced motor improvements and LEDD reduction than the young group, as well as worsening rigidity. Despite limited follow-up, the study showed that DBS should indeed be considered for the elderly population. Another comparison study that assessed psychiatric adverse effects on a young group (average age of 53 years) versus an elderly group (average age of 63 years) reported a higher incidence of serious adverse events in the older cohort. ${ }^{9}$ However, these events were largely transient in both populations, further suggesting that advanced age alone should not automatically dictate the exclusion of elderly patients for DBS. DeLong et al. ${ }^{11}$ showed comparable postoperative complication rates between young and old patients, indicating that although elderly patients may take longer to recover, they are not necessarily at a greater risk than the younger population.

As a whole, the comparable benefits of DBS surgery in the young and elderly patient populations can no longer be ignored, given the steady growth of our aging population. Rather, DBS should be viewed as a viable treatment for PD despite a patient's age, with emphasis placed on stringent preoperative assessment. As PD is one of the most common neurodegenerative diseases of aging, the prevalence and incidence are only expected to increase with the aging population, and so too should our repertoire of treatment options. We hope that this study may act to encourage further review of DBS use in elderly patient populations.

\section{Limitations}

Our study is not without limitations. We have presented retrospective data from a single academic center and single surgeon.

\section{Conclusions}

To date, and as per our knowledge, this is the first study to directly compare long-term results in the DBS treatment of PD in elderly and young patient populations. Our findings demonstrated that DBS treatment in the elderly was responsible for marked improvement in long-term motor function as evidenced by decreased UPDRS III scores, coupled with a significant reduction in medication requirements. When compared with younger patient populations, DBS treatment of the elderly demonstrated an equivalent reduction in UPDRS III scores, and a significantly larger reduction in LEDD and number of daily medication doses. The marked success of DBS in patients $\geq 70$ years when compared with a younger cohort makes a strong argument for the expansion of the therapeutic window for DBS patients based on age. Further studies will be conducted to expand on these findings, focusing on largescale investigations at longer time points. These authors hope that this study might supplement the literature for the treatment of PD in elderly populations, informing future medical and surgical decision-making.

\section{Acknowledgments}

We thank Mr. Jerry White for his contribution and constant support.

\section{References}

1. Anderson VC, Burchiel KJ, Hogarth P, Favre J, Hammerstad JP: Pallidal vs subthalamic nucleus deep brain stimulation in Parkinson disease. Arch Neurol 62:554-560, 2005

2. Benabid AL, Benazzouz A, Hoffmann D, Limousin P, Krack P, Pollak P: Long-term electrical inhibition of deep brain targets in movement disorders. Mov Disord 13 (Suppl 3):119-125, 1998

3. Beric A, Kelly PJ, Rezai A, Sterio D, Mogilner A, Zonenshayn M, et al: Complications of deep brain stimulation surgery. Stereotact Funct Neurosurg 77:73-78, 2001

4. Bronstein JM, Tagliati M, Alterman RL, Lozano AM, Volkmann J, Stefani A, et al: Deep brain stimulation for Parkinson disease: an expert consensus and review of key issues. Arch Neurol 68:165, 2011

5. Bronte-Stewart H: Parkinson's disease: surgical options. Curr Treat Options Neurol 5:131-147, 2003

6. Castrioto A, Lozano AM, Poon YY, Lang AE, Fallis M, Moro E: Ten-year outcome of subthalamic stimulation in Parkinson disease: a blinded evaluation. Arch Neurol 68:1550-1556, 2011

7. Charles PD, Van Blercom N, Krack P, Lee SL, Xie J, Besson $\mathrm{G}$, et al: Predictors of effective bilateral subthalamic nucleus stimulation for PD. Neurology 59:932-934, 2002

8. Chiou SM: Benefits of subthalamic stimulation for elderly parkinsonian patients aged 70 years or older. Clin Neurol Neurosurg 149:81-86, 2016

9. Cozac VV, Ehrensperger MM, Gschwandtner U, Hatz F, Meyer A, Monsch AU, et al: Older candidates for subthalamic deep brain stimulation in Parkinson's disease have a higher incidence of psychiatric serious adverse events. Front Aging Neurosci 8:132, 2016

10. Dafsari HS, Reker P, Stalinski L, Silverdale M, Rizos A, Ashkan K, et al: Quality of life outcome after subthalamic stimulation in Parkinson's disease depends on age. Mov Disord 33:99-107, 2018

11. DeLong MR, Huang KT, Gallis J, Lokhnygina Y, Parente B, Hickey P, et al: Effect of advancing age on outcomes of deep brain stimulation for Parkinson disease. JAMA Neurol 71:1290-1295, 2014

12. Derost PP, Ouchchane L, Morand D, Ulla M, Llorca PM, Barget M, et al: Is DBS-STN appropriate to treat severe Parkinson disease in an elderly population? Neurology 68:1345-1355, 2007 
13. Deuschl G, Schade-Brittinger C, Krack P, Volkmann J, Schäfer H, Bötzel K, et al: A randomized trial of deep-brain stimulation for Parkinson's disease. N Engl J Med 355:896908, 2006

14. Dorsey ER, Constantinescu R, Thompson JP, Biglan KM, Holloway RG, Kieburtz K, et al: Projected number of people with Parkinson disease in the most populous nations, 2005 through 2030. Neurology 68:384-386, 2007

15. Eskandar EN, Flaherty A, Cosgrove GR, Shinobu LA, Barker FG II: Surgery for Parkinson disease in the United States, 1996 to 2000: practice patterns, short-term outcomes, and hospital charges in a nationwide sample. J Neurosurg 99:863-871, 2003

16. Fasano A, Romito LM, Daniele A, Piano C, Zinno M, Bentivoglio AR, et al: Motor and cognitive outcome in patients with Parkinson's disease 8 years after subthalamic implants. Brain 133:2664-2676, 2010

17. Fraix V, Houeto JL, Lagrange C, Le Pen C, Krystkowiak $\mathrm{P}$, Guehl D, et al: Clinical and economic results of bilateral subthalamic nucleus stimulation in Parkinson's disease. J Neurol Neurosurg Psychiatry 77:443-449, 2006

18. Fukaya C, Yamamoto T: Deep brain stimulation for Parkinson's disease: recent trends and future direction. Neurol Med Chir (Tokyo) 55:422-431, 2015

19. Goldenberg MM: Medical management of Parkinson's disease. P\&T 33:590-606, 2008

20. Hauser RA: Long-term care of Parkinson's disease. Strategies for managing "wearing off" symptom re-emergence and dyskinesias. Geriatrics 61:14-20, 2006

21. Kalia LV, Lang AE: Parkinson's disease. Lancet 386:896912, 2015

22. Kim HY, Chang WS, Kang DW, Sohn YH, Lee MS, Chang JW: Factors related to outcomes of subthalamic deep brain stimulation in Parkinson's disease. J Korean Neurosurg Soc 54:118-124, 2013

23. Lenz FA, Schnider S, Tasker RR, Kwong R, Kwan H, Dostrovsky JO, et al: The role of feedback in the tremor frequency activity of tremor cells in the ventral nuclear group of human thalamus. Acta Neurochir Suppl (Wien) 39:54-56, 1987

24. Lewis SJ, Foltynie T, Blackwell AD, Robbins TW, Owen AM, Barker RA: Heterogeneity of Parkinson's disease in the early clinical stages using a data driven approach. J Neurol Neurosurg Psychiatry 76:343-348, 2005

25. Mathkour M, Garces J, Scullen T, Hanna J, Valle-Giler E, Kahn L, et al: Short and long-term outcomes of deep brain stimulation in Parkinson's disease patients 70-years and older. World Neurosurg 97:247-252, 2017

26. Okun MS, Gallo BV, Mandybur G, Jagid J, Foote KD, Revilla FJ, et al: Subthalamic deep brain stimulation with a constantcurrent device in Parkinson's disease: an open-label randomised controlled trial. Lancet Neurol 11:140-149, 2012

27. Ondo W, Jankovic J, Schwartz K, Almaguer M, Simpson RK: Unilateral thalamic deep brain stimulation for refractory essential tremor and Parkinson's disease tremor. Neurology 51:1063-1069, 1998

28. Ory-Magne F, Brefel-Courbon C, Simonetta-Moreau M, Fabre N, Lotterie JA, Chaynes P, et al: Does ageing influence deep brain stimulation outcomes in Parkinson's disease? Mov Disord 22:1457-1463, 2007

29. Pollak P, Fraix V, Krack P, Moro E, Mendes A, Chabardes S, et al: Treatment results: Parkinson's disease. Mov Disord 17 (Suppl 3):S75-S83, 2002

30. Pouratian N, Thakkar S, Kim W, Bronstein JM: Deep brain stimulation for the treatment of Parkinson's disease: efficacy and safety. Degener Neurol Neuromuscul Dis 2012:S25750, 2012
31. Puig-Junoy J, Puig Peiró R: [Review of the economic evidence on the use of deep brain stimulation in late stage Parkinson's disease.] Neurologia 24:220-229, 2009 (Span)

32. Schuepbach WM, Rau J, Knudsen K, Volkmann J, Krack P, Timmermann L, et al: Neurostimulation for Parkinson's disease with early motor complications. N Engl J Med 368:610-622, 2013

33. Shan DE, Wu HC, Chan LY, Liu KD: Cost-utility analysis of Parkinson's disease. Acta Neurol Taiwan 20:65-72, 2011

34. St George RJ, Nutt JG, Burchiel KJ, Horak FB: A metaregression of the long-term effects of deep brain stimulation on balance and gait in PD. Neurology 75:1292-1299, 2010

35. Stocchi F: The levodopa wearing-off phenomenon in Parkinson's disease: pharmacokinetic considerations. Expert Opin Pharmacother 7:1399-1407, 2006

36. Sugiyama K, Nozaki T, Asakawa T, Koizumi S, Saitoh O, Namba H: The present indication and future of deep brain stimulation. Neurol Med Chir (Tokyo) 55:416-421, 2015

37. Vesper J, Haak S, Ostertag C, Nikkhah G: Subthalamic nucleus deep brain stimulation in elderly patients - analysis of outcome and complications. BMC Neurol 7:7, 2007

38. Voges J, Hilker R, Bötzel K, Kiening KL, Kloss M, Kupsch A, et al: Thirty days complication rate following surgery performed for deep-brain-stimulation. Mov Disord 22:14861489,2007

39. Weaver FM, Follett K, Stern M, Hur K, Harris C, Marks WJ $\mathrm{Jr}$, et al: Bilateral deep brain stimulation vs best medical therapy for patients with advanced Parkinson disease: a randomized controlled trial. JAMA 301:63-73, 2009

40. Williams A, Gill S, Varma T, Jenkinson C, Quinn N, Mitchell R, et al: Deep brain stimulation plus best medical therapy versus best medical therapy alone for advanced Parkinson's disease (PD SURG trial): a randomised, open-label trial. Lancet Neurol 9:581-591, 2010

41. Zhu XL, Chan DT, Lau CK, Poon WS, Mok VC, Chan AY, et al: Cost-effectiveness of subthalmic nucleus deep brain stimulation for the treatment of advanced Parkinson disease in Hong Kong: a prospective study. World Neurosurg 82:987-993, 2014

42. Zibetti M, Merola A, Rizzi L, Ricchi V, Angrisano S, Azzaro C, et al: Beyond nine years of continuous subthalamic nucleus deep brain stimulation in Parkinson's disease. Mov Disord 26:2327-2334, 2011

\section{Disclosures}

The authors report no conflict of interest concerning the materials or methods used in this study or the findings specified in this paper.

\section{Author Contributions}

Conception and design: Kahn, Houghton, Smith. Acquisition of data: Hanna, Scullen, Mathkour, Evans. Analysis and interpretation of data: Hanna, Scullen, Kahn, Mathkour. Drafting the article: Gouveia, Hanna, Scullen, Kahn, Mathkour, Garces, Evans. Critically revising the article: Gouveia, Hanna, Smith. Reviewed submitted version of manuscript: Gouveia, Hanna, Smith. Administrative/technical/material support: Bui, Sulaiman. Study supervision: Lea, Biro, Smith.

\section{Correspondence}

Edna Gouveia: Ochsner Clinic Foundation, Jefferson, LA. v-egouveia@ochsner.org. 